\title{
Renovar a ética sexual cristã na pós- modernidade: educar o humano superando a tirania do prazer e do corpo fragmentado
}

\author{
Renew sexual ethics christian in post-modern: \\ educate human overcoming pleasure tyranny and \\ fragmentation body
}

André Luiz Boccato de Almeida

\section{Resumo}

O presente artigo apresentará quatro referenciais propositivos para uma ética sexual de inspiração cristã. Levando em conta que vivemos sob a égide de certa tirania do prazer e do corpo fragmentado, ambas devedoras do contexto pós-moderno, destacamos como necessário re-propor um olhar positivo sobre a realidade complexa da sexualidade humana a partir da ótica cristã. Torna-se imprescindível repensar o ser humano a partir de uma antropologia integral que reassuma uma visão de corporeidade positiva.

Palavras-chave: Ética sexual. Pós-modernidade. Prazer. Corpo. Educação.

\section{Abstract}

This article will feature four propositional reference to sexual ethics of Christian inspiration. Taking into account that we live under the aegis of certain tyranny of pleasure and fragmented body, both liable for the postmodern context, we highlight as necessary to re-propose a positive look at the complex reality of human sexuality from a Christian perspective. We 
emphasize that it is essential to rethink the human being from an integral anthropology reassume a positive view of corporeality.

Keywords: Sexual ethics. Postmodernity. Pleasure. Body. Education.

\section{Introdução}

Vivemos numa época caracterizada por uma grande incerteza e tensão, em todas as esferas da vida, e principalmente no que se refere à vivência dos valores. Os três elementos que, no passado, ofereciam segurança família, religião e comunidade - vão perdendo a própria influência frente ao devastador contexto pós-moderno. O ser humano encontra-se sozinho diante de seus problemas, não sabendo lidar com o prazer, dimensão fundamental de sua vida, e nem com o seu corpo que, agora fragmentado, também propicia uma visão ambivalente de si mesmo como sujeito no mundo. O prazer, que em décadas passadas era uma dimensão existencial não valorizada, passa a ser, a todo momento e de modo frenético, o centro da atenção da sociedade pós-moderna e pós-moralista. Neste sentido, o discurso cristão sobre a integralidade da pessoa e da sua expressão sexual também começa a sentir a necessidade de uma nova meta-narrativa. Queremos, mais que denunciar este processo tirânico e fragmentalizador do prazer e do corpo, propor alguns caminhos ético-educativos viáveis, para uma resignificação do humano que clama um corpo individualizadohumanizado e busca um sentido numa forma de prazer plena em comunhão com os outros enquanto propiciador para uma formação da consciência que vise à autonomia.

\section{Educar para uma visão integral da corporeidade}

A mentalidade pós-moderna impede que o ser humano pense a vida na sua totalidade. $\mathrm{O}$ corpo - realidade integral e a própria pessoa - tende a ser visto conforme o foco de quem olha a partir de interesses subjacentes. Sendo assim, torna-se necessário educar o olhar, isto é, educá-lo para uma integralidade que favoreça uma concepção que aqui chamaremos de "corporeidade". A corporeidade não é um elemento inteiramente acidental, mas uma realidade fundamental, tanto do ponto de vista do ser quanto do existir. Todo indivíduo 
deve aceitar e amar o próprio corpo e compreender a sua própria linguagem que o corpo fala. Fala a quem o possui e aos outros. A corporeidade é um fator estruturante do nosso psiquismo e da nossa personalidade. A soma das representações do corpo e dos seus órgãos, a assim chamada imagem corpórea, é muito importante para a formação do Eu. ${ }^{1} \mathrm{O}$ corpo não é somente uma soma de sensações e de inter-relações psíquicas. É um meio de comunicação, uma via privilegiada para se entrar em relação com os outros. Diz, sobre isso, Dacquino:

De fato, além de se exprimir com a voz, o homem "fala" também com os olhos, com o sorriso, com as mãos, com todo o corpo. Existe, então, com a linguagem verbal, também uma linguagem "não verbal", ou "corpórea", que se exprime com os movimentos dos olhos, os gestos da cabeça, as várias posições do corpo, as roupas, o odor, o calor, etc. ${ }^{2}$

Somos seres biológicos, psicoafetivos, sociais, éticos e espirituais. O corpo não é só o biológico isoladamente. Ele é esse todo que se manifesta segundo cada uma dessas dimensões. Contudo, não podemos negar que é na materialidade do corpo que se cruzam prazeres e desprazeres. É também na materialidade do corpo que se concentram todos os poderes e saberes. É nele, ainda, que a sexualidade encontra sua sede, pois:

É para caracterizar a complexidade das muitas dimensões que constituem nosso corpo (biológica, social, psicológica, ética, cósmica, etc.), que atualmente se prefere falar em "corporeidade", ou "corporalidade", em vez de se falar de corpo. A corporeidade é experiência vivida do corpo como realidade fenomenológica. ${ }^{3}$

A corporeidade ou corporalidade é, segundo Zilda Ribeiro, própria do humano. Ultrapassa o fenômeno físico e não se identifica com ele. $\mathrm{O}$ termo corporalidade se dá:

Como a confluência das exigências da exegese, da fenomenologia e da filosofia existencial, conforme o pensamento contemporâneo de ultrapassar as dicotomias grega e cartesiana da alma e do corpo. A corporalidade

\footnotetext{
${ }^{1}$ Cf. DACQUINO, G. Viver o prazer. São Paulo: Paulinas, 1992, p. 47.

${ }^{2}$ DACQUINO, G. Viver o prazer, p. 48.

${ }^{3}$ MOSER, A. O enigma da esfinge. A sexualidade. $4^{\text {a }}$ ed. Petrópolis: Vozes, 2003, p. 60.
} 
designa uma modalidade primitiva do homem inteiro que só pode ser tematizada por uma reflexão transcendental. ${ }^{4}$

Durante séculos, fomos devedores de uma concepção de corpo totalmente desprezada em detrimento da alma. Não se falava em corporeidade. Em nossos dias, por outro lado, predomina a imagem visual, a televisão, o cinema; e os jornais impõem à atenção modelos estéticos um tanto elevados e inalcançáveis, do físico atlético do esportista ao flexível da bailarina, do belo rosto da apresentadora ao imponente jovem ator ou cantor. Tudo isto comporta, para o "indivíduo comum", uma maior dificuldade em aceitar-se e em valorizar-se, inclusive corporalmente. ${ }^{5}$ Filosoficamente, a categoria de corpo contribui enormemente para uma visão integral de corporeidade. Lima Vaz nos ajuda a compreender que essa categoria filosófica pode ser a possibilidade de superação de todo dualismo, quando relacionada com todas as dimensões humanas e integradas entre si. Diz ele:

Pelo corpo o homem está presente no mundo. Mas, segundo se entenda o corpo como totalidade físico-orgânica e o corpo como totalidade intencional, é oportuno distinguir uma presença natural (presença impropriamente dita ou simples estar-aí) e uma presença intencional (presença no sentido próprio ou ser-aí). Pela primeira, o homem está no mundo ou na natureza em situação fundamentalmente passiva. Pela segunda, o homem está no mundo em situação fundamentalmente ativa, ou é ser-no mundo [...] Pela presença natural, o homem está presente no espaço-tempo físico e no espaço-tempo biológico do seu corpo que o situa no espaço-tempo do mundo. Pela presença intencional começa a estruturar-se o espaço-tempo propriamente humano, que tem no corpo próprio como corpo vivido o pólo imediato da sua estruturação para-osujeito, ou o lugar em que primeiramente se articulam o espaço tempo do mundo e o espaço-tempo do sujeito: psicológico, social e cultural. O corpo próprio pode ser chamado, assim, o lugar fundamental do espaço propriamente humano, e o evento fundamental do tempo propriamente humano. ${ }^{6}$

\footnotetext{
${ }^{4}$ RIBEIRO, Z. F. A mulher e seu corpo. Magistério eclesiástico e renovação da ética. Aparecida/SP: Santuário, 1998, p. 21

${ }^{5}$ Cf. DACQUINO, G. Viver o prazer, pp. 66-67.

${ }^{6}$ VAZ, H. C. L. Antropologia Filosófica I. $3^{\text {a }}$ ed. corrigida. São Paulo: Loyola, 1993, pp. 176-177.
} 
Queremos ressaltar o conceito de corpo que englobe a totalidade do ser humano, como ser aberto e com inúmeras possibilidades e disposições, cujas relações e ações ampliam o próprio corpo. Corpo-relação-consigo-próprio na integridade e, ao mesmo tempo, relação-com-o-Outro-e-os outros. No processo de educar para uma visão integral da corporeidade, é fundamental elucidar alguns "atentados" contra a consciência humana que impedem uma visão integral. Um primeiro "atentado" é fruto da cultura "perturbada" que vivemos, que nos manipula, gerando equívocos entre imagem e realidade:

Numa sociedade alienada, toda atividade perde o significado pessoal, e este fica substituído por uma imagem. A perturbação esquizóide gera a dissociação entre a imagem e a realidade. O termo "imagem" refere-se a símbolos e criações mentais em oposição à realidade da experiência física [...] A imagem é uma concepção mental que, superposta ao ser físico, reduz a existência corporal a um papel secundário. $\mathrm{O}$ corpo transforma-se num instrumento da vontade a serviço da imagem. A pessoa fica então alienada da realidade de seu corpo. Ao enfatizar em demasia o papel da imagem, ficamos cegos à realidade da vida do corpo e de seus sentimentos. ${ }^{7}$

Portanto, a educação para uma visão integral da corporeidade necessita de um olhar crítico sobre todas as imagens que nos são impostas e pelas quais somos bombardeados por todos os lados. Questioná-las é um exercício de busca da integralidade. Um outro caminho educativo para favorecer uma verdadeira e integral corporeidade é a consciência de que o corpo humano não existe isoladamente: ele é parte integrante da vida do planeta e de todo o sistema cósmico. ${ }^{8}$

Nesse sentido, o corpo não está separado da pessoa que pensa e age. Ele é a pessoa à medida que existe. Não basta apenas falar sobre a importância do corpo mas, sim, resgatar em um processo educativo a longo prazo sua dignidade e integralidade. Esta integralidade se dá no reconhecimento da ampla importância para a consciência humana da experiência.

Percebemos a urgência de uma educação para uma visão integral da corporeidade que possa gerar um novo modo de interpelar o humano diante da cultura hodierna. A educação moral e o empenho moral propõem-se o

\footnotetext{
${ }^{7}$ RIBEIRO, Z. F. A mulher e seu corpo. Magistério eclesiástico e renovação da ética. Aparecida/SP: Santuário, p. 24.

${ }^{8}$ CAVALCANTE, M. O corpo essencial. Trabalho corporal integrado para o desenvolvimento de uma nova consciência. Rio de Janeiro: Rosa dos Tempos, p. 209.
} 
mesmo fim que é a realização do ser humano como pessoa pela interiorização dos valores morais. A corporeidade, enquanto estrutura condicionante da vida pessoal, marca profundamente todo o dinamismo moral da pessoa. Destacamos a imprescindível urgência em se falar da positiva visão cristã de corpo e sexualidade no atual contexto em que vivemos. Educar para uma visão integral da corporeidade é buscar a plenitude do humano no cotidiano da vida, pois a pessoa realiza a totalidade do seu projeto ético graças ao fato de existir "na carne", isto é, por meio da sua condição corporal. A visão cristã da corporeidade, enquanto totalidade do ser humano, é uma proposta integradora que nos possibilita uma maior busca de equilíbrio e uma superação dos extremismos, principalmente, a tirania do prazer. Sobre esta proposta,

A corporeidade é, de fato, o modo específico de existir e de operar próprio do espírito humano. Este significado é, antes de mais, de natureza antropológica: o corpo revela o homem, exprime a pessoa, e é por isso a primeira mensagem de Deus ao próprio homem, quase uma espécie de primordial sacramento, entendido como sinal que transmite eficazmente no mundo visível o mistério invisível escondido em Deus desde a eternidade. ${ }^{9}$

Pelo corpo, portanto, existimos no mundo e revelamos nossa identidade de seres abertos à transcendência e não apenas à imanência. $\mathrm{O}$ corpo revelando o homem a ele mesmo e ao outro, também revela o Outro, isto é, Deus: “[...] o corpo contribui a revelar a Deus e o seu amor criador, enquanto manifesta a criaturalidade do homem, a sua dependência de um dom fundamental, que é o dom de amor". ${ }^{10}$ Portanto, a educação para um sentido pleno da corporeidade passa pelo cultivo e sentido da dimensão transcendente nas relações consigo e com o outro. Só educa para a integralidade integrante do corpo quem se deixa penetrar por este sentido existencial e de completude como manifesta a visão cristã. Este caminho exige uma trajetória de discernimento espiritual.

\section{Educar para o discernimento e a autonomia relativa}

As novas tecnologias da informação e telecomunicação deram origem a novos tipos de espaço, alterando nossa relação com o mundo físico e com as

\footnotetext{
${ }^{9}$ CONGREGAÇÃO PARA A EDUCAÇÃO CATÓLICA. Orientações educativas sobre o amor humano. Linhas gerais para uma educação sexual. São Paulo: Paulinas, 1983, no 22.

${ }^{10}$ Idem, $\mathrm{n}^{\mathrm{o}} 23$.
} 
inúmeras situações complexas. Temos dificuldade de decidir porque perdemos a visão do todo e, assim, não conseguimos discernir. Não conseguindo discernir, sentimo-nos frágeis em nossa autonomia. Já que o discernimento está em função da decisão, esta só se entende a partir da liberdade fundamental do projeto, isto é, uma liberdade situada em diálogo com outras liberdades. Considerando a complexidade cultural e humana, queremos propor a retomada do discernimento para o exercício da autonomia. Sabemos que,

A palavra "discernir" sugere, inclusive etimologicamente, o fato de ver entre duas (ou mais) possibilidades: ver com clareza qual é a doutrina verdadeira; qual é a opção acertada. Ora, todo homem se acha em situação de discernir, isto é, de descobrir de forma consciente e livre os motivos para uma boa escolha. Para escolher bem é suficiente que aquele que discerne seja prudente, pois, como dizia Tomás de Aquino: "o conselho (ou discernimento prévio à escolha) pertence à prudência". Toda pessoa deve ser prudente porque está chamada a escolher e para isto deve saber discernir. $^{11}$

Em se tratando de discernimento, dimensão fundamental da vida moral, três questões devem ser consideradas: qual é o resultado ou a meta a ser alcançada? (consequencialista); qual é a obrigação ou o dever a ser cumprido? (não-consequencialista); qual indicação o contexto ou a situação oferece para se poder assumir uma postura ética? (contextualista). São três perguntas diferentes que orientarão a tomada de decisões de modos diferentes, com resultados diferentes; são instrumentos valiosos para a análise ética e explicam por que as pessoas chegam a conclusões morais diferentes diante de um mesmo fato. ${ }^{12}$ Qual a relação entre o constante exercício do discernimento e a busca da autonomia? Segundo Azpitarte:

O sujeito que discerne não é um absoluto incondicionado, mas o que se encontra já com uma série de influências que escapam do ordinário de sua vontade. Nunca se situa de forma neutra diante de suas decisões, pois já está afetado por sua estrutura psicológica, com todo o mundo de experiências passadas e de sentimentos diante do futuro, que o estão condicionando. Esforçar-se por reconhecer a situação pessoal concreta

\footnotetext{
${ }^{11}$ BELLOSO, J. M. R. “Quem é capaz de discernir?”. Concilium 139 (1978), pp. 85-86.

${ }^{12}$ Cf. MAY, R. H. Discernimento moral. Uma introdução à ética cristã. São Leopoldo: Sinodal/ EST, 2008, pp. 55-56.
} 
a partir da qual se efetua é uma condição imprescindível para não espiritualizar excessivamente o que se explica por outras razões. ${ }^{13}$

Dentro deste raciocínio, destacamos que o discernimento não se realiza de forma simples e automática. É fruto de um constante exercício de auto-conhecimento. Está engajado e recebe a sua luz não apenas e nem principalmente da fria claridade da racionalidade científica, mas da qualidade humana e espiritual do sujeito. ${ }^{14} \mathrm{~A}$ doutrina tomista já tentava conjugar o discernimento prudencial ao julgamento da reta consciência, enquanto esteja sob o dinamismo da virtude da prudência. Para Tomás de Aquino, a prudência é a reta razão no agir, ${ }^{15}$ ou seja, a retidão prática que ordena o ser humano ao bem e exige do agente moral a retidão. Nessa perspectiva, são os fins da vida humana que remetem aos valores fundamentais em torno dos quais se organizam as virtudes e a vida humana. A prudência não pode determinar os meios de chegar a estes fins, a não ser que sua intenção habitual esteja assegurada pelas virtudes morais. ${ }^{16}$

O discernimento necessita da prudência. Um auxilia o outro e, ambos, levam à uma autonomia frente às situações da vida. $\mathrm{O}$ discernimento prudencial aparece como atividade fundante para o ser humano, levando-o a se confrontar lucidamente com todos os fatores implicados numa determinada situação real. Este discernimento tem um vínculo estreito com a responsabilidade e a autonomia, pois:

Todo homem está chamado a ser responsável perante os problemas que atingem a ele e a seu mundo. E na medida desta responsabilidade, o homem deve discernir a resposta mais adequada aos problemas de seu próprio ser e de seu derredor, de tal forma que nesta sua decisão o homem possa conhecer-se a si mesmo: aberto a uma relação com os outros e situado em alguns condicionamentos determinados. Desta maneira o "eu", as relações e os condicionamentos são conhecidos no ato de discernir e transformados pelos efeitos da decisão. ${ }^{17}$

\footnotetext{
${ }^{13}$ AZPITARTE, E. L. "Discernimento". In: COMPAGNONI, F.; PIANA, G.; PRIVITERA, S. (Eds.). Dicionário de Teologia Moral. São Paulo: Paulus, 1997, pp. 234.

${ }^{14}$ SIMON, R. "A lei moral e o discernimento". Concilium 139 (1978), p. 74.

${ }^{15}$ Cf. TOMÁS DE AQUINO. Suma teológica. São Paulo: Loyola, 2004, q. 47, a. 2.

${ }^{16}$ Cf. SIMON, R. “A lei moral e o discernimento”. Concilium 139 (1978), p. 76.

${ }^{17}$ BELLOSO, J. M. R. “Quem é capaz de discernir?”. Concilium 139 (1978), p. 86.
} 
Uma verdadeira educação para o discernimento e para a autonomia percorre duas etapas fundamentais, que integram em si a dimensão religiosa do ser humano: "uma primeira, purificadora, que converge para um autêntico conhecimento de si em Deus e de Deus na própria história, na própria vida, e uma segunda, na qual o discernimento se torna habitus". ${ }^{18}$ A primeira etapa, purificadora, traz em si um elemento substancial para o exercício do discernimento: a memória. Esta nos coloca em contato com nossa história, desejos, sentimentos, pensamentos e relações, já que:

É a capacidade de desenvolver com cuidado e atenção para aprender a discernir e adquirir uma atitude constante de discernimento [...] $\mathrm{O}$ discernimento que leva a esse evento fundante se baseia na integralidade cognoscitiva do homem, para poder seguir a inspiração interior do Espírito [...] Trata-se não de se conhecer sozinho, mas de adquirir, por meio do discernimento, a atitude fundamental do diálogo, de abertura, do descobrir-se dentro de uma relação cuidada. ${ }^{19}$

O ser humano pós-moderno, fragmentado e destituído de sua memória histórica, necessita de um processo educativo que leve em conta tanto o discernimento como a memória, em contínua relação com as pessoas que também facilitam, no diálogo, o encontro consigo mesmas, impelindo-as a viverem autenticamente. Para que o discernimento se torne um habitus, além de resgatar a dimensão memorial da história individual e ampla da pessoa em relação, torna-se fundamental aprender a estabelecer relações que sejam significativas. Nesse sentido, necessitamos, além do discernimento, educar e formar o ser humano para que seja menos individualista (narcísico) e mais relacional. A pósmodernidade, radicalizando a individualidade, impede que o sujeito cresça equilibradamente nas relações com os outros, correndo o risco de levar a pessoa a se adentrar num verdadeiro ostracismo.

Portanto, educar para o discernimento e para a autonomia, no atual contexto pós-moderno implica abertura às indagações do tempo presente em comum acordo com as potencialidades que o ser humano traz em si. Uma proposta moral externa e autoritária não educa, mas impede que a pessoa floresça. Por outro lado, somente cultivando a responsabilidade na convivência, será possível respeitar a autonomia de cada ser humano, e assim,

${ }^{18}$ BELLOSO, J. M. R. “Quem é capaz de discernir?”. Concilium 139 (1978), p. 32.

${ }^{19}$ BELLOSO, J. M. R. “Quem é capaz de discernir?”. Concilium 139 (1978), pp. 32-33. 
erigir o discernimento como a sabedoria que possibilita a reflexão e a vivência prudencial em meio às decisões a se tomar diariamente. Uma pessoa que discerne prudencialmente busca um sentido pleno do prazer.

\section{Educar para um sentido pleno do prazer}

As novas gerações não se pautam mais pelo dever. Pautam-se pela vazão e realização imediata do prazer. A valorização do "eros" pode desestimular o pensar. Estímulos contínuos para a vivência "aqui e agora" impedem a criação dinâmica de um projeto de vida. Por fim, a desumanização sutil e inconsciente vaga sobre essa égide do total desfrute do prazer. A idéia de educar o prazer em conformidade com a busca da felicidade de forma equilibrada é tão antiga quanto as formulações éticas. Nesta busca de educar o prazer e a vida afetiva em seu todo, pretendia-se dar respostas aos anseios humanos mais profundos:

Aristóteles via na vida afetiva o próprio objeto da moral: os problemas humanos ou aqueles que concernem aos caracteres e às paixões. Santo Tomás não pensará de forma diferente. Para ele a vida afetiva (que chama de vis apetitiva, o desejo) é o objeto "material" da moral, e as virtudes morais, ou seja, os dinamismos estruturados e estruturantes da maneira de agir, são as que humanizam essa força apetitiva, pelo jogo moderador e finalizante da inteligência que é a razão do amor. Poderíamos dizer que o homem moral é um ser cuja vida afetiva possui "músculos": ela é forte, hábil, capaz de adaptação e fonte de prazer. ${ }^{20}$

Entre a felicidade e o prazer não deveria existir oposição. Mas quando o prazer é tratado de modo absoluto, corre-se o risco de vivê-lo como fim e não como meio, tornando-se incapaz de ajudar a ir além de si mesmo. No contexto pós-moderno, o prazer imediato é tratado como totalidade, despersonalizando e desumanizando o ser, podendo impedir a busca contínua rumo a uma felicidade que se realiza como um processo. A pós-modernidade abandona a idéia da gradualidade da experiência do prazer, como também a de amadurecimento gradativo da pessoa, pois descarta a memória histórica e afetiva, focandose no indivíduo enquanto sujeito que quer se realizar no imediato momento, mesmo que para isso, deva compensar os vazios existenciais de inúmeros

${ }^{20}$ PLÉ, A. Por dever ou por prazer. São Paulo: Paulinas, 1984, p. 137. 
modos segundo o prazer individualizado. Notamos o quão necessário hoje repropor a gradual busca pela maturidade.

Esta é o resultado de nossa história evolutiva, consciente e inconsciente. Quer dizer, ela pressupõe um desenvolvimento adequado das diferentes capacidades e disposições psíquicas: sublimação das pulsões instintivas, por conseguinte, atenuação das ambivalências (reações violentas de ódio e amor), capacidade de oblatividade e de reciprocidade nas relações com os outros. Essa maturidade é própria do indivíduo integrado, isto é, em harmonia com as pulsões, os desejos e os pensamentos de seu psiquismo. ${ }^{21}$

Destacamos que o desejo, que impele ao prazer, não poderia ser reduzido numa vivência restrita do genital, como vem sendo manipulada pela mídia e pelo capital de consumo. Notamos que culturalmente há o impedimento de uma vivência integral do prazer imposto por esses mecanismos da civilização e da cultura; por outro, há um impedimento ontológico e existencial arraigado na cultura, esvaziando o sentido personalista do prazer. Precisamos questionar a mentalidade reinante, destacando que:

A criança que deseja que os pais satisfaçam suas pulsões parciais, vai enfrentar negativas que vão obrigá-la a crescer e a mudar a maneira de gratificar-se. Embora, durante a infância, a busca do prazer domine o psiquismo, progressivamente a criança terá que aprender que o prazer para o consciente é uma consequência e não um fim como o é para o inconsciente. Este estado de tensão será fonte de conflitos durante toda a existência. Desta impossibilidade de obter imediatamente tudo o que se quer, nasce a pulsão, mas também o trabalho do desejo. ${ }^{22}$

A pessoa necessita, portanto, desde a infância, de uma educação para o sentido pleno do prazer. Esta será a base do processo de humanização que se dá durante toda a vida. O caminho não deve ter como critério a total satisfação dos prazeres imediatos. A tensão consequente é benéfica quando o amor é o fim e o prazer, um meio para fortificá-lo. Na verdade, o prazer do amor sexual, como o salientam os povos e as religiões orientais há milênios, é a máxima expressão do prazer humano, só comparável ao estado de plenitude da

${ }^{21}$ DACQUINO, G. Viver o prazer, p. 116.

22 JUNGES, J. R. "Ética sexual e novos padrões culturais". Perspectiva Teológica 71 (1995), p. 74 . 
divindade. Um prazer todo ele nascido e impregnado de amor, de ternura, de encontro profundo de dois seres humanos que se dão a si mesmos na máxima expressão de entrega. Os limites do prazer são previamente estabelecidos, como nos outros casos, quando possam representar um dano à própria pessoa ou uma lesão aos direitos de outra pessoa ou da sociedade. Se o prazer é um bem e se não prejudica a própria saúde física ou psíquica de alguém ou de terceiros, não se vê por que motivo tenha que ser algo intrinsecamente mau. ${ }^{23}$

Educar para o sentido do prazer no contexto pós-moderno não é uma tarefa simples. É um processo a longo prazo, que caminha junto com o exercício do discernimento e a formação da consciência. Requer do educador uma atitude de constante flexibilidade, já que o protagonista não é ele, mas o próprio indivíduo que sente a necessidade de integrar o prazer no todo da sua vida e que tem consciência de que é um ser prenhe de contradições e desejos contrapostos.

Portanto, a tarefa de uma ética sexual cristã, no contexto hodierno, dá-se pela busca de um sentido pleno do prazer. Esta configura-se pelo questionamento da cultura do descartável, presente numa concepção ética utilitarista pósmoderna. Também, por uma formação que conduza a um processo de respeito pela individualidade de cada pessoa e a sua responsabilidade diante das decisões a serem tomadas.

\section{Educar para uma vivência plena da sexualidade}

Seguindo apenas os impulsos, não se consegue viver a sexualidade de forma autenticamente humana. Faz-se imprescindível propor uma educação que se conecte com todas as dimensões humanas, em direção de uma superação do estágio infantil e egoísta no qual só se busca a satisfação imediata dos próprios apetites e caprichos. Se se quiser alcançar um mínimo de maturidade e equilíbrio humano, a conduta, aberta para qualquer possível configuração, necessita de um esforço ascético e de uma séria dose de renúncia. ${ }^{24}$ Contudo, vivência plena da sexualidade depende da antropologia subjacente. Percebemos que:

\footnotetext{
${ }^{23}$ BENETTI, S. Sexualidade. Como vivê-la de maneira criativa. São Paulo: Paulinas, 1996, pp. 114-115.

${ }^{24}$ AZPITARTE, E. L. Ética sexual. Masturbação, homossexualismo, relações pré-matrimoniais. $2^{\circ}$ ed. São Paulo: Paulinas, 1991, p. 7.
} 
Diante de uma visão muito espiritualista e uniforme, como a que se viveu até tempos recentes, encontramo-nos hoje no meio de uma sociedade que apresenta diferentes antropologias sexuais de signo muito contrário à anterior. Se antes era a alma que se devia livrar de todas as ataduras e escravizações do corpo, para alcançar certo nível de espiritualização, agora é o corpo que deve se despojar de tudo o que the impeça sua expressão mais espontânea e natural. A permissividade absoluta e um naturalismo biológico são os denominadores comuns de muitas correntes modernas. ${ }^{25}$

O discurso ético, propiciando certa sustentação teórica a uma visão de sexualidade, projeta o ser humano em um projeto de vida amplo. Um dado inicial e importante para se pensar a sexualidade num sentido pleno, é o de que a ética dá sustentação a uma visão integrada de sexualidade à medida que esta é compreendida em um projeto de vida amplo. Um critério norteador para a vivência integral da sexualidade é o de optar por uma verdadeira antropologia unitária e não dualista do ser humano. O dualismo, que historicamente se revestiu ora de rigorismo, ora de permissividade, se fundamenta numa antropologia que separa radicalmente psiquismo e matéria, racional e biológico. O peso que se atribui a cada um desses elementos leva ao rigorismo ou à permissividade. ${ }^{26}$

Toda tentativa de se aproximar do homem de hoje a partir de uma ótica dualista acha-se condenada ao fracasso, pelo perigo de cair em qualquer dos dois extremos. A eliminação do sentido psicológico e transcendente da matéria, ou o esquecimento da condição encarnada do espírito, dá ao ser humano caráter demasiado animal ou excessivamente angélico. Não podemos negar que vivemos ainda sob o império de um dualismo, no entanto, este agora se centraliza mais na dimensão físicocorporal erótica, dissociando o sexo da sexualidade, ou seja,

O sexo dissociado da sexualidade encontra sua satisfação em puras técnicas sem viver plenamente a sexualidade. O equilíbrio de uma personalidade não se regenera numa vida genital intensa, mas no desenvolvimento de uma sexualidade fonte de vida relacional. A dissociação entre sexo e sexualidade leva a não conseguir integrar a pulsão sexual por falta de recursos internos. O que desintegra não são acontecimentos, situações ou crises mas a maneira de interpretá-los e assumí-los. A personalidade

\footnotetext{
${ }^{25}$ AZPITARTE, E. L. Ética da sexualidade e do matrimônio. São Paulo: Paulus, 1997, p. 11.

${ }^{26}$ Cf. AZPITARTE, E. L. Ética da sexualidade e do matrimônio, p. 25.
} 
precisa elaborar interiormente estes elementos, mas para poder fazê-lo, necessita de uma interioridade. O sexo separado da verdadeira relação intersubjetiva perde seu sentido e torna-se deprimente. ${ }^{27}$

Salientamos a urgência de situar a sexualidade num contexto mais amplo, que é o da relação intersubjetiva, não reduzindo-a a uma simples vivência isolada de modo egocêntrico e narcísico. Por sua vez, o cristianismo nos oferece também não só uma concepção de sexualidade, mas, principalmente um critério norteador que dá embasamento a uma visão relacional. Há uma visão antropológica positiva do magistério da Igreja, quando assim se manifesta:

A sexualidade é uma componente fundamental da personalidade, um modo de ser, de se manifestar, de comunicar com os outros, de sentir, de expressar e de viver o amor humano. Ela é parte integrante do desenvolvimento da personalidade e do seu processo educativo. ${ }^{28}$

Esta perspectiva possibilita situar a sexualidade em um paradigma ético intersubjetivo, enquanto "locus" de uma verdadeira realização no amor. O amor humaniza a sexualidade e a conduz a uma busca integral do prazer. No atual contexto pós-moderno encontramos neste texto do magistério a possibilidade de promover uma ética do amor e da sexualidade como experiência de abertura de si ao outro. O ser humano é chamado a se abrir e desabrochar suas potencialidades ao longo de sua vida, integrando amor e sexualidade. Entre ambas destacamos que há uma relação profunda, pois ambas são a condição para a comunicação e a abertura ao outro.

O amor só é possível se duas pessoas se comunicam mutuamente a partir do centro de suas existências e, portanto, se cada uma se experimenta a partir do centro de sua própria existência. Só nesta "experiência central" existe realidade humana, só aí há vivacidade, só aí está a base do amor. ${ }^{29}$ A relação de abertura ao outro - epifania do amor - propicia superar a fase inicial de orfandade. A busca pelo amor transforma a pessoa em amado e

\footnotetext{
${ }^{27}$ JUNGES, J. R. "Ética sexual e novos padrões culturais". Perspectiva Teológica 71 (1995), pp. 72.

${ }^{28}$ CONGREGAÇÃO PARA A EDUCAÇÃO CATÓLICA. Orientações educativas sobre o amor humano. Linhas gerais para uma Educação Sexual. São Paulo: Paulinas, 1983, nº 4.

${ }^{29}$ FROMM, E. A arte de amar. $4^{\text {a }}$ ed. Belo Horizonte: Itatiaia Limitada, 1964, p. 101.
} 
amante. Destacamos que amar está em íntima conexão com ser amado. Para amar precisamos aprender e educar o amor. Ele necessita ser purificado das impressões sensitivas e narcísicas, fazendo brotar uma verdadeira relação intersubjetiva. Não podemos negar que,

É bem verdade que o ambiente consumista de nossa sociedade dificulta uma ética baseada na moderação e na espera de um futuro melhor, pois não se suporta a tensão de uma necessidade presente nem se aceita o desprazer provocado por uma ascética educativa. A fome de consumo converteu o sexo em uma fonte de prazer, deixando o homem em uma etapa primária de sua evolução. ${ }^{30}$

Uma desconstrução da mentalidade cultural é benéfica quando o que está em jogo é o humano. Este itinerário de melhor compreensão do contexto vigente proporciona-nos a busca por uma explicitação ética do sentido humano. Torna-se fundamental resgatar uma antropologia integral e unitária, superando resquícios dos dualismos passados, mas ao mesmo tempo evitando parciais visões que poderiam conduzir a uma ética fragmentária. $\mathrm{O}$ amor vivido como oblação é o ideal da perspectiva ética cristã. Portanto, o termômetro do verdadeiro amor não é o "eu" ensimesmado ou narcísico - que exige um prazer imediatamente - mas o "outro" que se envolve com o "eu", chamando-o a ser o que é: companhia. Neste sentido, uma vivência plena da sexualidade leva em conta a satisfação relacional que o outro sente.

\section{Conclusão}

O diálogo, a reciprocidade e a abertura são valores fundamentais que tocam profundamente o sujeito pós-moderno. Quisemos salientar a urgência de uma ética sexual cristã que se coloque em um processo de revisão diante do atual ethos. Vemos como necessário pensar em uma ética fundamentada em uma pedagogia criativa e crítica que faça emergir os limites da mentalidade que enaltece excessivamente a busca por um prazer existencial que gera uma cultura do corpo sensível como único locus de realização humana. Os quatro passos educativos - uma visão integral da sexualidade; a busca por um discernimento enquanto autonomia relativa; um sentido pleno

${ }^{30}$ AZPITARTE, E. L. Ética sexual. Masturbação, homossexualismo, relações pré-matrimoniais, p. 10. 
do prazer, e, a vivência integrante da sexualidade - configuram-se como passos reflexivos diante de uma nova antropologia por vir. A tradição cristã pode também indicar elementos humanistas que nos faça ir além de uma tirania do prazer e do corpo fragmentado. Em última instância, o ser humano tem a responsabilidade ética pela própria construção da sua identidade, em conformidade com a sua dignidade, em harmonia com o sentido mais profundo de sua existência.

\section{Referências bibliográficas}

AZPITARTE, E. L. "Discernimento". In: COMPAGNONI, F.; PIANA, G.; PRIVITERA, S. (Eds.). Dicionário de Teologia Moral. São Paulo: Paulus, 1997, pp. 229-239.

AZPITARTE, E. L. Ética sexual. Masturbação, homossexualismo, relações pré-matrimoniais. $2^{\mathrm{a}}$ ed. São Paulo: Paulinas, 1991.

AZPITARTE, E. L. Ética da sexualidade e do matrimônio. São Paulo: Paulus, 1997.

BELLOSO, J. M. R. “Quem é capaz de discernir?”. Concilium 139 (1978), pp. 84-93.

BENETTI, S. Sexualidade. Como vivê-la de maneira criativa. São Paulo: Paulinas, 1996.

CAVALCANTE, M. O corpo essencial. Trabalho corporal integrado para o desenvolvimento de uma nova consciência. Rio de Janeiro: Rosa dos Tempos, 1992.

CONGREGAÇÃO PARA A EDUCAÇÃO CATÓLICA. Orientações educativas sobre o amor humano. Linhas gerais para uma educação sexual. São Paulo: Paulinas, 1983.

DACQUINO, G. Viver o prazer. São Paulo: Paulinas, 1992.

FROMM, E. A arte de amar. $4^{\mathrm{a}}$ ed. Belo Horizonte: Itatiaia Limitada, 1964.

JUNGES, J. R. "Ética sexual e novos padrões culturais”. Perspectiva Teológica 71 (1995), pp. 65-81.

MAY, R. H. Discernimento moral. Uma introdução à ética cristã. São Leopoldo: Sinodal/EST, 2008. 
MOSER, A. O enigma da esfinge. A sexualidade. $4^{\text {a }}$ ed. Petrópolis: Vozes, 2003.

PLÉ, A. Por dever ou por prazer. São Paulo: Paulinas, 1984.

RIBEIRO, Z. F. A mulher e seu corpo. Magistério eclesiástico e renovação da ética. Aparecida/SP: Santuário, 1998.

SIMON, R. “A lei moral e o discernimento”. Concilium 139 (1978), pp. 74-83.

TOMÁS DE AQUINO. Suma teológica. São Paulo: Loyola, 2004, q. 47, a. 2.

VAZ, H. C. L. Antropologia Filosófica I. $3^{\text {a }}$ ed. corrigida. São Paulo: Loyola, 1993.

André Luiz Boccato de Almeida

Doutor em teologia moral e bioética - Pontificia Università Lateranense (Roma) Professor na Pontifícia Universidade Católica de São Paulo Professor na Faculdade de Teologia do Mosteiro de São Bento/SP São Paulo / SP - Brasil E-mail: a.1.boccato@gmail.com

Recebido em: 28/09/2016

Aprovado em: 07/02/2017 